\title{
Bank-Insured RoSCA for Microfinance: Experimental Evidence in Poor Egyptian Villages
}

\author{
Mahmoud El-Gamal, Mohamed El-Komi, \\ Dean Karlan and Adam Osman*
}

September 2011

\begin{abstract}
Microfinance institutions (MFIs) have continued to grow over the past few decades, both in numbers of clients and portfolio sizes. The growth of these MFIs has enabled greater access to credit in many of the world's less developed nations. However, recent studies have shown that very many of the poor - especially Muslims - remain unbanked, and many who have access to banks remain credit constrained. Confounding this problem in many Muslim countries is the poor's propensity to reject microfinance, when available, on religious grounds. In this paper we propose an alternative microfinance model built on the familiar rotating savings and credit association (RoSCA) model that is Islamically accepted, and test its performance against sequential Grameen-style microcredit provision in a "laboratory experiment in the field" conducted in poor Egyptian villages. Our model of bank-insured RoSCAs is shown to solve coordination-failure problems that may otherwise prevent the spontaneous development of informal RoSCAs in practice. Empirically, our guaranteed-RoSCA model generated significantly higher takeup and repayment rates than the Grameen model, suggesting that this model can be a useful alternative for Islamic countries where many of the poor have rejected conventional modes of microfinance.
\end{abstract}

\footnotetext{
* Rice University and James A. Baker III Institute for Public Policy (El-Gamal); Durham University (ElKomi); Yale University and Innovations for Poverty Action (Karlan); Yale University (Osman). We are grateful to the Kelly Day Endowment at the Baker Institute for Public Policy for generous funding. We are also grateful to Dr. Ibrahim Rihan and Eng. Mohamed Melouk of the Egyptian Ministry of Local Development for indispensable support and cooperation. Last but not least, we are grateful to workshop and conference participants at UT-Dallas, Rice and University of Houston, and AALIMS inaugural conference at Duke, as well as the African Econometric Society meetings at the American University in Cairo and the Economic Science Association Conference in Chicago.
} 


\section{Introduction}

Despite advances made by microfinance institutions in giving the poor access to credit, recent studies have estimated that 2.7 billion adults in the developing world remain unbanked, cf. CGAP (2009). Even among those who have access to some basic banking services, there is evidence of significant credit constraints, cf. Banerjee and Duflo (2004). Confounding this problem in the Middle East are religious and social injunctions, especially in the modern era for Muslims, against interest-based borrowing, grounded in the ancient prohibition of usury.

In this regard, the Muslim poor, in particular, have shown significant rates of rejection of traditional microloans. This coincides with large, and in some cases increasing, incidences of poverty and financial exclusion among Muslim populations. Researchers from the Islamic Development Bank estimated that in the six countries with largest Muslim populations (Indonesia, India, Pakistan, Bangladesh, Egypt and Nigeria) the number of people living on less than $\$ 2$ per day far exceeds half a billion (their estimate is 628 million), cf. Obaidullah and Khan (2008) . Recent studies have also included survey results that show Muslims to be highly excluded from access to banking products and services, with exclusion rates reaching as high as $80 \%$ in India. Finally, for Muslims with access to microloans, surveys have suggested that up to $40 \%$ reject such loans on religious grounds, cf. CGAP $(2008,2009)$.

Despite the fast growth of "Islamic finance," its ability to engage the Muslim poor, who comprise half of all the Muslims in the world, has been meager. As of 2008, "Islamic microfinance" was estimated to reach only 380,000 customers, only one half of one percent of total microfinance outreach, cf. CGAP (2008). A few recent papers (cf. Ahmed (2002); Dhumale and Sapcanin (1998); Abdul Rahman (2007)) have attempted to explain the current progress or lack thereof, but it is safe to say that the religious-legal-arbitrage methods used in "Islamic Finance" (cf. El-Gamal (2006)), which have met some success among the middle and upper classes, have not been sufficiently appealing to the poor.

The impact of microfinance on poverty alleviation is not as significant or well established as one might think, ${ }^{1}$ and the objective of this study does not extend to measuring

\footnotetext{
${ }^{1}$ Early studies that established positive effects have included Pitt and Khandker (1998), which exploited eligibility criteria at three Bangladeshi Microfinance institutions (MFIs). However, Roodman and Morduch (2009) found these early results to be questionable after analyzing the same non-experimental data. Experimental studies have reported generally positive or neutral effects of microfinance. For example, Banerjee et al. (2009) studied the introduction of microcredit into a new market in randomly selected Hyderabad slums. They found an increase in MFI borrowing in the treated areas along with an increase in expenditure on durable goods and new business investments. Significant positive impacts on household health and education were not found in their study, but the authors contend that it may take more time for significant differences to be observed. In another randomized study in peri-Urban Manila, Karlan and Zinman (2010) have found that, if anything, business size was reduced, and no change in consumption was observed, but that income did increase for men. Using a similar
} 
the impact of microfinance availability. Our objective is simply to compare the rates of takeup and repayment in a standard model of interest-based sequential group microlending (as practiced earlier, for instance, by the Grameen Bank of Bangladesh) and an alternative model that builds on the indigenous rotating savings and credit association (RoSCA), known in Egypt as the gam 'iya. This institution is used extensively and was approbated by both classical and contemporary Islamic jurists, including the most conservative. ${ }^{2}$ Our focus is on rates of takeup and strategic default under these models.

The two models we test are similar in structure but differ fundamentally with regards to the bank's involvement. In what we call the Grameen model (sequential lending to members of the group) the bank plays an active role by injecting capital through its initial loan, collects interest on the loan, and penalizes all group members in the case of default by any group member. Players are allowed to extend a one-period interest-free loan to their partners who may otherwise default, in order to avoid bank penalties. We experiment with low, medium, and high levels for these penalties and analyze the experimental subjects' behavior under the different designs.

In the insured-RoSCA model, the group members lend capital to each other, without interest, and the the bank takes a relatively passive initial role as a guarantor. The bank charges a small fee for its credit-insurance services. In case of non-repayment by a RoSCA member, the bank takes that member's place to keep the RoSCA going, and treats the defaulting member as a debtor responsible to repay the bank both principal and interest.

In this study we conduct laboratory experiments in the field, using very poor subjects in rural Egypt who are eligible for microloans, and compare the takeup and repayment rates of randomly assigned subjects under the two designs. We find that the RoSCA model performs significantly better with regards to takeup, and no worse with regards to repayment, when compared to the Grameen model. The rest of the paper proceeds as follows: In Section 2, we outline the extensive forms of a sequential Grameen-style microlending structure as well as our proposed alternative, a bank-insured fixed-order RoSCA, and analyze the equilibria for different parameter values. In Section 3, we describe the experimental design and the demographics of our sample. In Section 4, we report and discuss the results of statistical data analyses. Section 5 concludes the paper, acknowledging the limited scope of its results, and anticipating future directions for research.

randomized evaluation methodology, Karlan and Zinman (2009) looked at the expansion of consumer credit in South Africa and found that increased access to credit for marginal applicants significantly improved outcomes: Treated borrowers were found to be more likely to retain their job, less likely to experience hunger, and having more positive outlooks on life.

${ }^{2} \mathrm{~A}$ list of the positive opinions, ranging from neutral permissibility to positive approbation are listed in Arabic in a study by Dr. A. Al-Jibrin, and posted at: http://www.mktaba.org/vb/showthread.php?t=13001 (accessed May 23, 2011). Moreover, there is reason to believe that mutual structures such as credit unions built on RoSCAs are consistent with the letter and spirit of classical Islamic jurisprudence, cf. El-Gamal (2007). 


\section{Models}

Our baseline model represents a variation on the classical peer-monitoring microfinance model used by many MFIs around the world, most famously by Grameen Bank. The alternative model that we propose utilizes the familiar fixed-order rotating savings and credit association model combined with a banker (in our case the experimenter) as guarantor (henceforth, guaranteed-RoSCA, or RoSCA model for short).

There is an extensive theoretical economics literature on RoSCAs, which are generally treated as part of informal finance. Recently, Ambec and Treich (2007) showed that RoSCAs are similar to other pre-commitment mechanisms to enhance savings, one of the vehicles through which microfinance is likely to help alleviate poverty. In a series of influential papers, Besley et al. $(1992,1993,1994)$ had earlier analyzed the mechanisms and efficiency properties of various RoSCA structures, concluding that some types of RoSCAs enhance welfare through credit provision. Random-turn RoSCAs were seen to perform particularly well in theory, ${ }^{3}$ but we restrict attention in our study to standard RoSCAs with fixed collection order, because bidding and random RoSCAs are not common in the Middle East, and may be considered akin to gambling, which is also forbidden in Islamic scripture, along with usury or ribā (interpreted most widely by contemporary Muslim jurists and laity as the prohibition of interest-based loans, regardless of the interest rate). ${ }^{4}$

We address the possibility of coordination failure ${ }^{5}$ in the informal RoSCA structure by introducing bank insurance, whereby the banker guarantees the stream of payments and loans to any member of the RoSCA who continues to make required payments on time. Those who default become debtors to the bank, and if they default on their debt to the bank, the latter applies the same group punishment as in the Grameen design (a proxy for all types of punishments exercised in reality, including exclusion from access to credit for a period, reduction of credit ceilings, etc.). Thus, our two models are similar to some extent, with the notable difference that the Grameen model starts with loans from the bank, and allows for within-group loans in case of impending default, while the alternative design starts with RoSCAs and allows for indebtedness to the bank in case of impending default.

\footnotetext{
${ }^{3}$ RoSCAs with random allocation were found to be superior when individuals have identical tastes. In Besley et al. (1994), the authors compared bidding RoSCAs and random ones to formal credit markets. They found that the allocations achieved by credit markets were more efficient than those reached by bidding RoSCAs. However, random RoSCAs were found under certain conditions to yield higher level of ex ante expected utility.

${ }^{4}$ The Arabic riba shares the root, meaning, and scriptural prohibition of the Hebrew ribitt, which coincides with interest in many but not all contract forms, cf. El-Gamal (2003). The second Islamic financial prohibition is against gharar, or excessive and unnecessary risk taking, which would not invalidate non-commutative financial contracts. It would be possible to structure "Islamic" variations on the random-order RoSCA, but we decided to use the fixed-order form because of its familiarity.

${ }^{5}$ By "coordination failure," we refer to the possibility of subjects failing to begin a RoSCA on their own due to the uncertainty surrounding the likelihood of group members defaulting strategically on their obligation to the RoSCA or failing otherwise to make their periodic contributions.
} 
Both models include a penalty $p$ for defaulting on debts to the bank, which is charged to all players in the defaulter's group. We also introduce a penalty $q$, which is a proxy for loss of social capital when one defaults on debt to another individual. The true value of this penalty is unknown ex-ante and applies only to the defaulter. It must be noted that $q$ may be nontrivial, as Karlan (2007) has observed significant loss of social capital due to loan defaults in Peru.

The models differ on one other key dimension: the timing of payments. In the Grameen model, the second player need not contribute capital in round one, whereas in the RoSCA model, the second player is effectively a lender to the first player in round one. To focus strictly on other aspects of the model, we assume that the second player has no outside option, e.g. in the form of investment or expedited consumption. This assumption is not unreasonable if we think that most investments require a fixed cost greater than what prospective micro-investors can individually afford and they are otherwise credit constrained. Similarly, our design affords clients a dynamic incentive due to imminent loans that may be sufficient to forego current consumption temptations. ${ }^{6}$

\section{I The Grameen Game}

The extensive form representation of a simplified sequential microfinance model (henceforth, Grameen) is shown in Figure 1. Each player starts with one unit of capital and has the opportunity to partake in an investment opportunity that will return the principal and yield an additional guaranteed return of $2 r$ after one period (this "return" could also serve as a measure of incremental utility from consumption smoothing). This opportunity requires an investment of two units of capital, which is currently out of the reach of the participant. She is then informed of her financing option, which in this case is a bank loan that requires repayment of principal plus interest at rate $i(i<2 r$, hence borrowing to invest is profitable).

In period $t=0$, Player 1 and Player 2 each have to decide whether or not to participate in sequential borrowing from the bank. If either player decides not to participate, the game ends in period $t=0$ with both players retaining their initial capital. We call this the "bad (or opt-out) equilibrium," because neither player receives a loan or invests, thus foregoing the value added from investment.

If they both choose to participate, Player 1 receives a loan from the bank, and invests

\footnotetext{
${ }^{6}$ Banerjee and Duflo (2011) dedicate most of their Chapter 8 to the question "why the poor don't save more," noting the difficulty that poor Indian women face to resist the temptation of spending their money on sweet tea. They refer to Ashraf et al. (2006) as an illustration of how "[d]esigning financial products that share the commitment features of the microfinance contracts, without the interest that comes with them, could clearly be of great help to many people", c.f. (Banerjee and Duflo, 2011, Kindle location 3222). Savings mobilization and credit provision with minimal cost along the equilibrium path is likewise a central objective of this paper.
} 


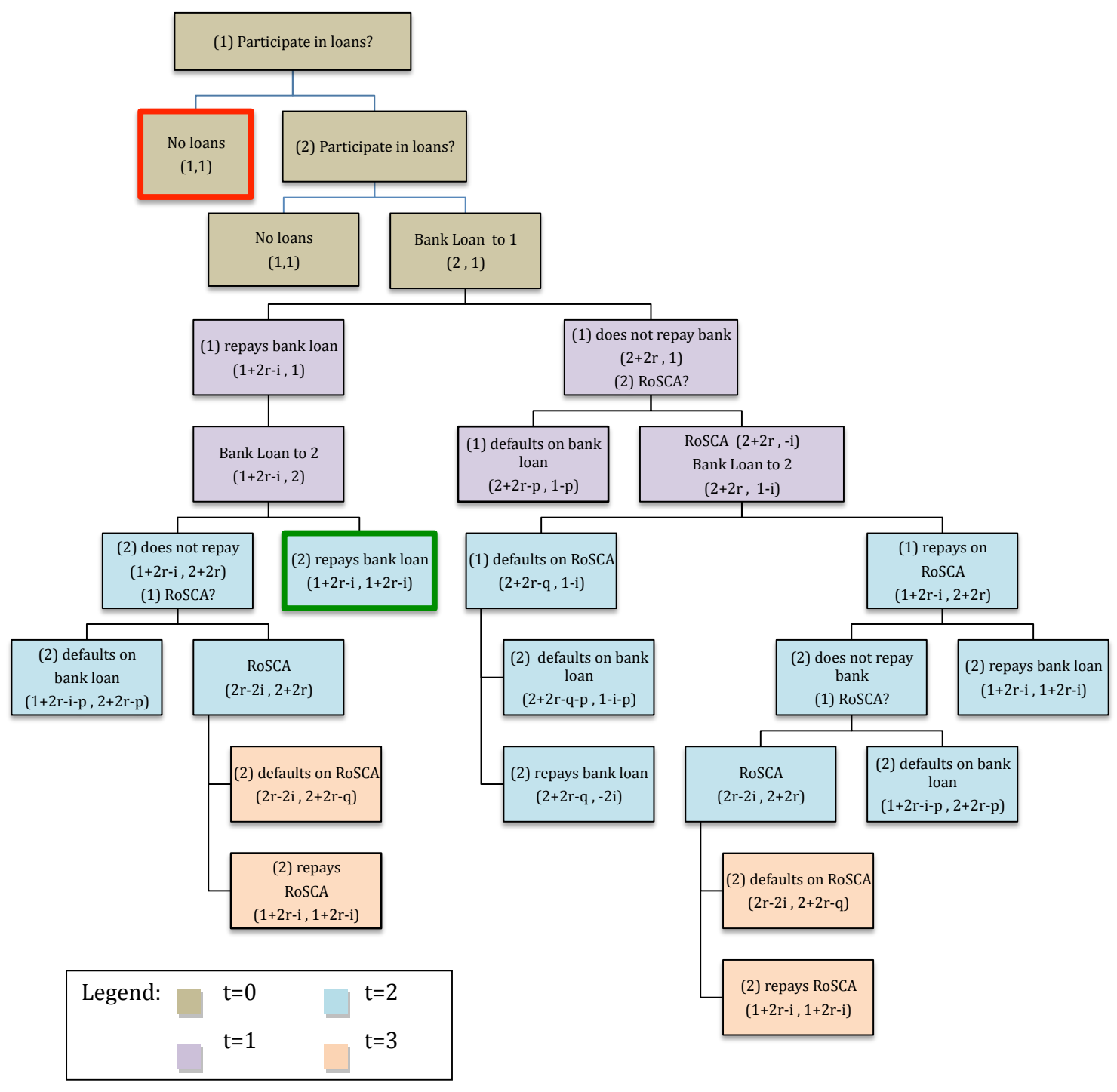

Figure 1: Grameen Extensive Form Game 
her capital in a project that has a guaranteed return $2 r$. After receiving her capital and profits, Player 1 has the option to repay her loan to the bank or to renege. If she chooses to repay, the bank will then extend a loan to Player 2, and we move to period $t=1$ along the left branch of the extensive form.

\section{The left branch}

In period $t=1$, along the left branch, Player 2 has the option to repay the bank, after investing and collecting his profits, at which point the game ends at $t=2$, or he can renege. If the game ends at $t=2$, we call this "the good equilibrium" (see analysis below), where each player received a loan, invested, received profits $2 r$ and paid interest $i<2 r$.

If Player 2 reneges, Player 1 has the option to pay off Player 2's debt and avoid the bank's penalty (a one period loan between the players). If Player 1 refuses, Player 2 would have defaulted and both players are punished by the bank (incurring penalty $p$ each). (Note: These inter-player loans would arise more naturally if negative income shocks were possible. In the current case, a default by Player 1 would arise only from moral hazard, ${ }^{7}$ and Player 2 may then be forced to pay off Player 1's debt in order to avoid incurring the high penalty $p$. We should not observe this behavior along the equilibrium path.)

If Player 1 repays Player 2's debt, we continue to period $t=3$ along the left branch, and Player 2 then has the opportunity to repay Player 1, in which case we get the same payoffs as the "good equilibrium," but because the path includes reneging, we consider this outcome inferior. If Player 2 chooses to default on the one period loan given to him by Player 1, then Player 1 loses her capital, and Player 2 keeps it along with profits, but suffers the social-capital penalty $q$ for defaulting on the loan from Player 1 . The game ends in either case.

\section{The right branch}

If we reach period $t=1$ after Player 1 reneges on her loan to the bank, Player 2 then has the opportunity to pay off her debt so as to avoid facing the bank's penalty for default, and losing the opportunity to receive a loan. If Player 2 decides against this then Player 1 would have defaulted, and the game ends at $t=1$ with both players suffering the penalty $p$.

If Player 2 pays off Player 1's debt, then we move to period $t=2$ along the right branch, with Player 2 receiving the bank loan, but not having enough to invest. Player 1 then has the opportunity to repay Player 2 or default on the loan Player 2 extended to her. If she defaults, she alone suffers the social penalty $q$. Player 2 may then repay his bank

\footnotetext{
${ }^{7}$ For example, there is evidence that some husbands have urged their wives strategically not to repay their loans to Grameen Bank, and measures to convince the husbands otherwise were needed, c.f. (Dowla and Barua, 2006, p. 150).
} 
loan (ending up with negative payment $=-2 i$ ), or default on the bank, ending up with $1-i-p$ and subjecting Player 1 to the penalty $p$ as well. In either case, the game ends in period $t=2$.

If Player 1 repays the inter-player loan, then as Player 2 gets this repayment, he can invest and earn the return $2 r$. If he repays the bank loan, then again the game ends in period $t=2$ with the same payoffs as the "good equilibrium," but the outcome is deemed inferior because the path involves reneging on the first bank loan.

If Player 2 does not repay the bank, Player 1 may pay it off for him. If she doesn't, then the game ends in period $t=2$ after both players incur the penalty $p$ for defaulting on the bank. If she does pay it off, then Player 2 may repay her, again reproducing the "good equilibrium" payoffs, but very inefficiently, or he may refuse to repay the loan, in which case he keeps the money but suffers (alone) the penalty $q$.

\section{Equilibrium Analysis}

First, we consider the case where $q$ is sufficiently high. Since we are assuming above that returns are guaranteed, $q$ is always incurred if one player repays the other's loan and interest to the bank, and then the debtor refuses to pay the other player back.

If $q>(1+i)$, there will never be any default on the inter-player loan. Therefore, each player knows that even if the other one were to default on the bank loan, they would not default on the loan that they receive from their partner. Therefore, by backward induction, both players will agree to the sequential loans, and both will repay their loans, ending at the "good equilibrium."

If $q<(1+i)$, then, unfortunately, a player would have the financial incentive to default on the loan from his partner. Regardless of whether $p$ is small or large, if Player 1 gets the bank loan, he would keep his $2+2 r$, and threaten to default on the bank loan. If Player 2 refuses to cover Player 1's debt, he ends up with $1-p$, and should have opted out. If Player 2 extends an implicit loan to Player 1, then Player 1 would default on it, and Player 2 would again end up with less than his capital, and would prefer to opt out. Therefore, if $q<(1+i)$, regardless of the value of $p$, the game should always end in the "bad equilibrium" with both players refusing to participate (again, for parsimony, because Player 1 knows that Player 2 will opt out when $q$ is small, she is indifferent between participation and opting out, and we choose the more efficient path to the same payoffs).

\section{Discussion}

This dichotomous result, depending only on whether or not $q$ is high, is not surprising.

\footnotetext{
${ }^{8}$ The same payoff can be reproduced along three other paths with no default on RoSCAs, but with delay. We assume that indifference between these nodes will always be resolved in favor of the most efficient.
} 
Grameen Bank and other microlenders often use peer monitoring, and at times shared liability, as mechanisms to leverage social capital of the micro-borrowers who are not likely to have other forms of collateral acceptable to the banks. Large $q$ is a proxy for high social capital. In practice, microfinance participants often form RoSCAs or otherwise extend credit to pay off debts of group members in order to avoid penalties, cf. (Armendáriz de Aghion and Morduch, 2005, p.88), which is also consistent with our analysis, assuming that $q$ is sufficiently high.

It is also noteworthy that the dichotomy for good vs. bad equilibrium does not depend on $p$. Perhaps this is one explanation for why Grameen Bank itself has fully abandoned the more draconian joint liability model and continued to experience high rates of repayment, ${ }^{9}$ cf. Dowla and Barua (2006). The model leverages the grouping of debtors, including the ability to borrow from the group fund, which is akin to RoSCA, using the subjects' social capital as collateral, i.e. relying on a high $q$. As we show later in this section, it may be superior to reverse the order of the bank's loan and the RoSCA, in the process obtaining good equilibrium behavior even when $q$ is not very high.

\subsection{The Guaranteed-RoSCA Game}

The extensive form of our Guaranteed-RoSCA Model is shown in Figure 2. The starting point is the same as in the Grameen game: Each player is endowed initially with one unit of capital, and faces the same opportunity to invest two units of capital (one of which must thus be borrowed) to earn a profit of $2 r$.

The two players have to decide whether or not to participate in sequential bankguaranteed RoSCAs. If they decide to proceed, they are required each to pay a fee to the bank, which will then guarantee the RoSCAs against default. It is assumed that this fee for participation is very small compared to capital, interest, and profit amounts (in our experiments, subjects paid an administrative fee of $s=i / 2$, half of the interest charge). Therefore, we ignore it in our analysis by subsuming it in the initial endowment. ${ }^{10}$ The game prompts players to form a RoSCA first and only requires bank intervention in the case of default. In other words, we reverse the order of events in the Grameen model. Since the RoSCA comes first, bank loans should be rare and defaults on bank loans even rarer still, thus making the insurance premium fee paid for participation minimal.

\footnotetext{
${ }^{9}$ (Armendáriz de Aghion and Morduch, 2005, p. 127) claim that Grameen loans "are seldom enforced exactly as they should be on paper." In the case of a group with one defaulting member and other group members who are still in good standing bank employees would attempt to get as much of the loan paid back as possible and then drop the defaulting member from the rest of the well-performing group, allowing them to continue their relationship with the bank.

${ }^{10}$ This fee is a sunk cost conditional on deciding to opt-in and does not effect equilibrium play beyond that decision. Empirically we find takeup of the RoSCA model to be higher than takeup of the Grameen model. Removing this fee should lead to even stronger results.
} 


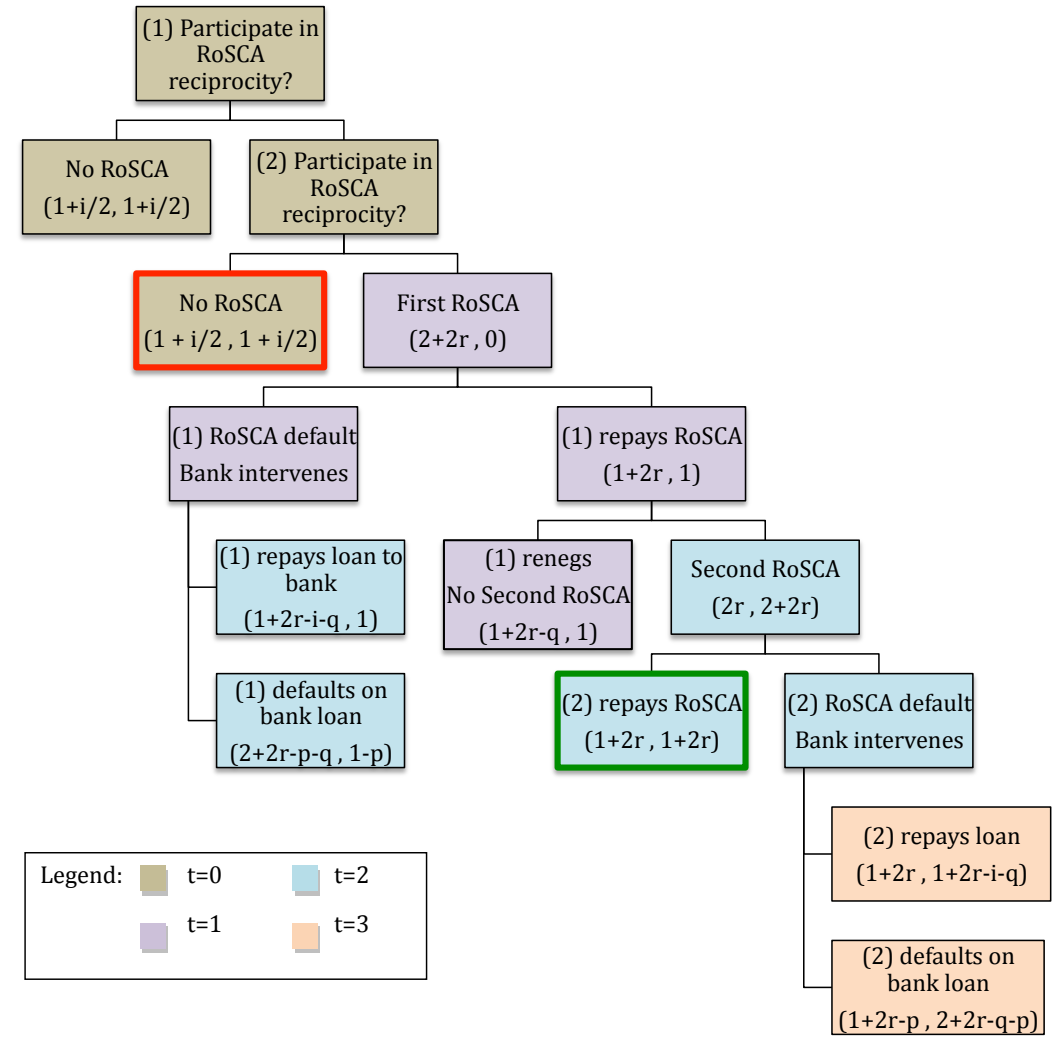

Figure 2: Guaranteed RoSCA Extensive Form Game 
If either player chooses to opt out of the game, we end up with the "bad equilibrium," each player keeping their capital and the game ending in period $t=0$. If they choose to participate and pay the small fee, ${ }^{11}$ we move into period $t=1$, with Player 1 receiving the first RoSCA, investing, and receiving the return $2 r$.

\section{Right branch}

Player 1 may then repay the RoSCA, along the right branch of the game. Player 1 may extend the second RoSCA, or she may choose to end the game in period $t=1$, suffering (alone) the social penalty $q$. Alternatively, she may choose to extend the second RoSCA to Player 2, in which case we move to period $t=2$ with Player 2 investing and receiving the return $2 r$.

Player 2 may then end the game in period $t=2$ by repaying the RoSCA, and we label this the "good equilibrium," which is only reproduced this way with both RoSCAs taking place and being repaid on time. Notice also that because the fee for participation is (assumed to be) smaller than the interest rate $i$, this is a more efficient outcome than the "good equilibrium" under the Grameen game.

Player 2 may also choose to default at $t=2$, in which case the bank intervenes to repay Player 1, and Player 2 suffers the social penalty $q$. If Player 2 then chooses to repay the bank loan, he also has to pay principal plus interest $1+i$. Alternatively, Player 2 may default on the bank loan, keeping $2+2 r-q$, and subjecting both players to the bank's default penalty $p$.

\section{Left branch}

If Player 1 chooses to default on the first RoSCA, then the bank intervenes to repay Player 2, and Player 1 suffers the social penalty $q$. In period $t=2$, Player 1 may then repay the bank $1+i$, or keep $2+2 r-q$ and both players suffer the default penalty $p$.

\section{Equilibrium analysis}

Even though the extensive form of this game is much simpler than our Grameen game, the equilibrium analysis is slightly more nuanced, and much more interesting.

If the social penalty $q>1$, the size of the interest free loan in the model, we never get defaults on RoSCAs, or reneging on promises to extend them, and obtain the "good equilibrium" in a straight forward way.

This already produces more "good equilibrium" outcomes for the range $1<q \leq$ $1+i$ under the guaranteed-RoSCA design, ${ }^{12}$ but only adds a relatively small range of

\footnotetext{
${ }^{11}$ We add the small fee to the original endowment instead of subtracting it from every future node, without loss of generality, for ease of representation in the extensive form.

${ }^{12}$ Throughout, we are assuming that the participation fee or insurance premium $s \ll i<2 r$.
} 
parameters. The more interesting result is that even if $q$ is small, where the Grameen design would yield only the bad equilibrium, a large value of $p$ can make it possible for the RoSCAs to take place.

If $p$ is sufficiently large, each player knows that the other player would rather not default on the bank loan. This in turn implies that each player would not default on a RoSCA, because that would trigger an automatic bank loan. The default on a RoSCA would result in a personal penalty $q$, and then either a payment of $1+i$ to the bank, or a penalty of size $p$ for both players.

Therefore, if $p>(1+i)$, the player would never default on the bank loan, and thus would be better off repaying the RoSCA (at 1 ) instead of repaying the bank loan (at $1+i$ ). This adds another large part of the parameter space, where $q<(1+i)$ but $p>(1+i)$, where the guaranteed RoSCA produces the "good equilibrium" but the Grameen model does not.

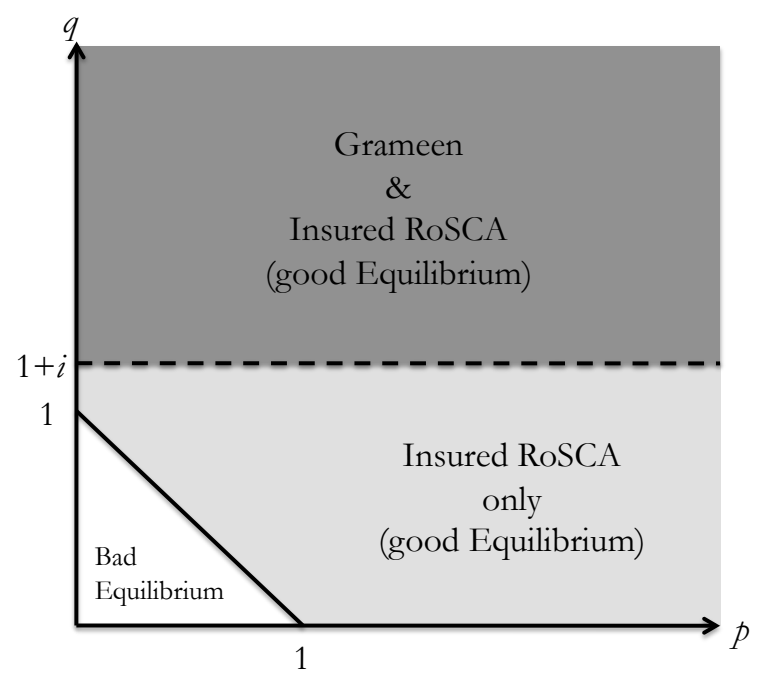

Figure 3: Equilibria for Various Parameter Values

Finally, there remains the case where neither $p$ nor $q$ are sufficiently large by themselves, but $p+q$ is sufficiently large. The relevant nodes for determining the threshold for $p+q$ are the nodes where a player contemplates defaulting on the RoSCA and then defaulting on the bank loan. In that case, they incur both penalties $p+q$, and get to keep the single unit borrowed under the RoSCA. Therefore, if $(p+q)>1$, we obtain the "good equilibrium" under the guaranteed RoSCA model, adding a large segment of the parameter space where we obtain the good equilibrium only under that model. 
One interesting interpretation is the following: $q$ may be high enough for the Grameen (and RoSCA) models to work, but subjects' beliefs about $q$ may be biased downward. In this case, there is coordination failure: If only subjects knew how high $q$ really was, they would spontaneously form RoSCAs, or at least accept microloans from Grameen-like banks. By introducing the bank as a guarantor of RoSCAs, with an announced $p>1-q$ (which can obviously be guaranteed without knowing $q$ by setting $p>1$ ), the coordination failure is solved, and the RoSCAs are formed, helping individuals to save and invest. In this case, the default rates should be extremely small, and therefore the participation fee (insurance premium) collected by the bank can be correspondingly small. ${ }^{13}$

Of course, the social penalty $q$ is unobserved, and the bank's collective penalty $p$ is a control parameter. In the experimental analysis below, we vary $p$ to test if the frequency of takeup increases in this parameter, as predicted by our model. For a fixed value of $p$, and assuming that pairs of subjects draw values of $q$ from some distribution, our analysis suggests that we should see more frequent takeup and repayment (the "good equilibrium") under the guaranteed RoSCA model as compared to the Grameen model. Our experimental results support this theoretical analysis.

\section{Experimental Design and Data}

We conducted a series of experiments in various poor villages in rural Egypt with the help of the Egyptian Ministry of Local Development (MoLD). Employees of MoLD, whom the local villagers trust as providers of microloans, ${ }^{14}$ were trained to conduct the experiments using the design and instructions translated in Appendix 3. In discussions with the experimenters and their senior leadership, we noted enthusiasm that the proposed model may improve on their current microfinance model in two ways: (1) reduce bureaucratic layers by relying on self organization of the community through their existing RoSCA and social networks, and (2) lower likelihood that RoSCA-based finance can drive the poor into debt traps, which some of the MoLD employees worried may be a very real possibility. ${ }^{15}$ In the meantime, many of the experimenters and senior leadership had healthy skepticism about the attractiveness of formalized RoSCAs: "Why wouldn't the borrowers set them up

\footnotetext{
${ }^{13}$ Assuming the insurance charges here are actuarially fair.

${ }^{14}$ MoLD has an ongoing project, the Local Development Fund (LDF) that has been active since the 1970s. The LDF offers small to medium size loans to entrepreneurs in most of the 29 governorates in Egypt (with very limited operations in Cairo and Alexandria), its operations suffer severe bureaucratic difficulties due to the cumbersome procedures of approving loans.

${ }^{15}$ Researchers have documented Grameen debtors turning to moneylenders to repay their debts, borrowing more to repay the latter, and so on, thus sinking into a debt trap; cf. Matin (1997).
} 
without our help?" they asked. Ultimately, they agreed that we should let the data inform us whether or not our design can incentivize them to form the RoSCAs.

\section{I Design and Location Selections}

The experiments were conducted during January-February, 2010. In preparation, the experimental team conducted pilot experiments in three villages in upper and lower Egypt during September-October, 2009, in part to refine the experimental design and instructions (for ease of understanding), as well as to measure the demographics in various villages and choose the ones most suited for the microfinance experiments. In the process, we decided to exclude a village that was too close to Cairo (Tahla, Qalyubia) where subjects had had considerable experience with microfinance institutions over the decades. Out of 20 models that we tested with 50 subjects, the two models described in Section 2 were selected for ease of understanding (we used "Monopoly" money in the pilots and real money in the actual experiments). The average payment per subject in the pilots was EGP $15(\approx$ $\$ 3$ at the exchange rate in 2009), which are sufficient to feed a household of four people at this poverty level for one day.

We selected one village Southwest of Cairo (Disya, Fayoum, one of the poorest areas in the country) and two villages Northwest of Cairo (Feesha and Aryamon, ${ }^{16}$ Beheira), also among the poorest. Loan officers were instructed to recruit subjects who would be interested in and eligible for a microloan (not exceeding EGP $1000 \approx \$ 190$ ). ${ }^{17}$ Senior loan officers and Ministry officers helped to ensure integrity of the recruitment process. More subjects than we could accommodate showed up for each session, and those who were turned back were paid a show up fee of EGP 5.

The initial capital given to each subject was EGP $14(\approx \$ 2.5)$, given in cash. The investment opportunity required EGP 20 , and promised a guaranteed return of the original capital along with an additional EGP 4 profit, also given in cash. Loans could only be taken in the amount of EGP 10, and the interest on a bank loan was EGP 2. The insured RoSCA participation fee was set at EGP 1. Subjects who participated kept the money in their possession at the end of the game, and collected a survey participation fee of EGP 5.

\footnotetext{
${ }^{16}$ We had planned to conduct two days of experiments in Feesha, Beheira. On the second day, however, word that researchers were giving out money to partake in a small game spread rapidly and we faced excessive demand for participation, with some subjects getting aggressive. The local officials were unable to calm the prospective subjects, and we were forced to move to nearby Aryamon instead. There is no reason to believe that the populations of these nearby villages within the same district differ significantly. Table 7 in Appendix 1 shows that the demographic characteristics of the subjects in the two villages were statistically equivalent, and very different from Disya, Fayoum.

${ }^{17}$ This strategy meant that our data may have potentially oversampled people that were already comfortable with the idea of microfinance in general. This may tilt our results in favor of the Grameen model, because those who reject interest-baring loans categorically would be less likely to respond to the recruitment call. This makes our result of higher takeup rates under the RoSCA model more remarkable.
} 


\subsection{Data}

We conducted a total of 12 experimental sessions in Fayoum, eight using the RoSCA and four using the Grameen design. We conducted 13 sessions in Beheira, six using the Grameen and seven using the RoSCA design. The total number of subjects was 354 . For logistical reasons, and to ensure that all subjects received the same instructions, we randomized treatment (Grameen vs. RoSCA design) by day. Within each day, we randomized the value of the penalty $p$ by session over the set \{zero, low=EGP 6 , medium $=$ EGP 11, or high=EGP 13\}. Player type (1 vs. 2) was randomized for each pair. At the beginning of each session, subjects sat in a large hall, listened to the instructions and watched an example game being demonstrated. The floor was then opened for questions which were answered in public. Subjects were then asked to choose a partner amongst those who were in the room. The numbers of observed games (i.e. pairs) for each location and design are shown in Table 1.

Table 1: Summary of Experimental Observations

\begin{tabular}{|c|c|c|c|c|c|}
\hline Governorate & Village & Day & Model & Penalty & \# Observations \\
\hline \multirow[t]{12}{*}{ Fayoum } & Disya & 1 & RoSCA & Zero & 0 \\
\hline & & & & Low & 7 \\
\hline & & & & Medium & 7 \\
\hline & & & & High & 14 \\
\hline & & 2 & Grameen & Zero & 6 \\
\hline & & & & Low & 14 \\
\hline & & & & Medium & 7 \\
\hline & & & & High & 7 \\
\hline & & 3 & RoSCA & Zero & 0 \\
\hline & & & & Low & 7 \\
\hline & & & & Medium & 14 \\
\hline & & & & High & 7 \\
\hline \multirow[t]{8}{*}{ Beheira } & Feesha & 4 & Grameen & Zero & 7 \\
\hline & & & & Low & 11 \\
\hline & & & & Medium & 10 \\
\hline & & & & High & 6 \\
\hline & Aryamon & 5 & RoSCA & Zero & 7 \\
\hline & & & & Low & 14 \\
\hline & & & & Medium & 15 \\
\hline & & & & High & 12 \\
\hline Total (Pairs) & & & & & 172 \\
\hline
\end{tabular}

Table 2 shows the distributions of variables that we use in our econometric analysis below, and Table 3 shows the distributions of demographic and socioeconomic variables. 
Table 2: Summary of Participant Demographics

\begin{tabular}{ccccccc} 
Governorate & Gender & $\%$ & $\begin{array}{c}\% \\
\text { literate }\end{array}$ & $\begin{array}{c}\% \\
\text { employed }\end{array}$ & $\begin{array}{c}\text { \% Head of } \\
\text { married }\end{array}$ & Household \\
\hline Fayoum & Male & 12 & 23 & 86 & 86 & 95 \\
& Female & 88 & 27 & 24 & 75 & 54 \\
\hline \multirow{3}{*}{ Beheira } & (Mean) & & 27 & 32 & 76 & 59 \\
& Male & 56 & 75 & 76 & 76 & 76 \\
& Female & 43 & 55 & 21 & 60 & 44 \\
\hline & (Mean) & & 66 & 52 & 69 & 62 \\
\hline
\end{tabular}

Table 3: Socioeconomic Data

\begin{tabular}{clccccc} 
Governorate & Variable & \# Obs & Mean & S.D. & Min & Max \\
\hline Fayoum & Age & 174 & 39 & 13 & 18 & 72 \\
& HH income & 137 & 283 & 174 & 30 & 1200 \\
& HH size & 180 & 5 & 2 & 1 & 11 \\
& Own TV? & 180 & 0.7 & 0.5 & 0 & 2 \\
& Own cell phone? & 180 & 0.3 & 0.5 & 0 & 3 \\
\hline Beheira & Age & 160 & 37 & 12 & 18 & 81 \\
& HH income & 151 & 337 & 227 & 40 & 1000 \\
& HH size & 163 & 5 & 2 & 1 & 15 \\
& Own TV? & 164 & 0.9 & 0.4 & 0 & 1 \\
& Own cell phone? & 164 & 0.5 & 0.5 & 0 & 1 \\
\hline
\end{tabular}

The overall illiteracy rate in our sample was 35\%. Less than half of our sample was unemployed, and most of the unemployed were women. In the meantime, nearly half of the women in our sample were the heads of their households. The average age of participants was 38 and the average monthly household income was EGP $300(\approx \$ 55$; i.e. our show-up fee for each subject was equal to the average household daily income). Almost every household in the sample owned a television set, and approximately $40 \%$ reported having a satellite dish connection (typically shared). Similarly, 36\% of the sample owned a cell phone. The socio-demographic data for the three villages reflect the overall poverty levels in the governorates, Fayoum being the second poorest in Egypt, and Beheira the 12th poorest, cf. UNDP (2008).

\subsection{Exploratory Data Analysis}

Table 4 shows the aggregate proportions of play (Opt Out; Good Equilibrium; or some Default) by experimental treatment (Grameen versus RoSCA). The takeup rates for the 
Grameen treatment were approximately 75\%, and for the RoSCA design were $91 \%$. "Good Equilibrium" play, where all loans are extended and paid back, was 63\% in the Grameen design and $82 \%$ in the RoSCA design. As predicted by our model, formal ANOVA tests (superseded by the regression analysis in Section 4) showed statistical significance of the higher takeup rates under the RoSCA design. For completeness, we also report the percentage of observations where some default occurred.

Table 4: Outcome by Model and Penalty

\begin{tabular}{llccc} 
Bank Penalty & Model & \% Opt Out & \% Good Eq. & \% Default \\
\hline Zero & Grameen & 15 & 46 & 38 \\
& RoSCA & 0 & 57 & 43 \\
\hline Low & Grameen & 32 & 56 & 12 \\
& RoSCA & 21 & 61 & 18 \\
\hline \multirow{2}{*}{ Medium } & Grameen & 29 & 71 & 0 \\
& RoSCA & 6 & 89 & 6 \\
\hline High & Grameen & 15 & 85 & 0 \\
& RoSCA & 3 & 97 & 0 \\
\hline \multirow{2}{*}{ Total } & & \%Opt Out & \%Good Eq. & \%Default \\
\hline \multirow{6}{*}{} & Grameen & 25 & 63 & 12 \\
& RoSCA & 9 & 82 & 10 \\
\hline
\end{tabular}

\section{Statistical Data Analysis}

We focus our formal statistical analysis in this Section on the two main results: (1) higher takeup rates, and (2) higher repayment rates under the RoSCA design. In Table 5, we report the results of estimating a logit model for the choice whether to opt out (column 1), as well as a conditional logit for the choice to defect conditional on takeup (column 2). We show the estimation results only for variables that are significant for at least one of the two estimations. Other variables such as household income, food intake, and other demographics were not significant for either regression and therefore we did not use them in the reported regressions for parsimony.

The estimation produces a number of interesting results, which we will explain later under the simple assumption that each pair draws a value of $q$ from some distribution. If this $q$ is sufficiently high (greater than $1+i$, which was EGP 12 in the experiments), our model predicts that we should observe the good equilibrium (takeup and no defects). In the RoSCA design, the frequency of defects should decline with $p$ as it brings $p+q$ above the threshold of 1 (EGP 10 in the experiments). The first major result in our esti- 
Table 5: Logit for Opt Out (1), and conditional logit for Defect given Takeup (2, Baseline $=$ Equilibrium) logit: Opt Out?

\begin{tabular}{lcc}
\hline RoSCA & $-1.282^{* *}$ & 0.216 \\
& $(-2.63)$ & $(0.31)$ \\
Penalty & -0.230 & $-1.611^{* * *}$ \\
& $(-0.97)$ & $(-3.88)$ \\
Both female & -0.340 & $1.501^{*}$ \\
& $(-0.65)$ & $(2.09)$ \\
At least 1 literate & $-1.373^{*}$ & $-1.988^{*}$ \\
& $(-2.45)$ & $(-2.27)$ \\
Governorate & $1.877^{* *}$ & $1.894^{*}$ \\
& $(3.13)$ & $(2.02)$ \\
Constant & -0.926 & \\
& $(-1.66)$ & 146 \\
\hline Observations & 172 & $\chi^{2}(5)=41.60$ \\
& $\chi^{2}(5)=22.06$ & Pseudo $R^{2}=0.398$ \\
\hline
\end{tabular}

$t$ statistics in parentheses

${ }^{+} p<0.1,{ }^{*} p<0.05,{ }^{* *} p<0.01,{ }^{* * *} p<0.001$
(1)

(2)

Defect

$(-3.88)$

$-1.988$

$(-2.27)$

$-0.926$

seudo $R^{2}=0.398$

mation supports this theoretical prediction: The decision whether to opt out or continue depends significantly on the design (higher chance for takeup under RoSCA), but not on the penalty, and the decision whether or not to default conditional on takeup depends on penalty (lower chance of defection under higher penalty) but not on the design. For example, for our low- $p$ design, the percentage of opting out in Beheira under the Grameen design (45\%) was more than double the same rate for the RoSCA design (21\%). Then, conditional on takeup, the percentage of defects in Beheira under low- $p$ design is nearly half, and drops precipitously for higher- $p$ designs.

There is no gender effect on the decision whether or not to opt out. In particular, both players being female does not influence the probability of opting out once we condition on the other reported variables. This suggests that microfinance designs that cater exclusively to women may not benefit from higher takeup rates because of this focus. It is important to note here that if we do not condition on governorate, then we do get a significant negative coefficient on the dummy variable for both players being female, but that serves merely as a proxy for the greater percentage of females in Fayoum, and we obtain the same significant effect for both players being male, again providing no evidence that catering exclusively to females increases takeup rates in our experiment. In the meantime, we get a result that both players being female increases the incidence of defects conditional on takeup. The 
flip-side of this result, because there were extremely few pairs of opposite sexes, is that we observe fewer defaults given takeup by males, perhaps because of differential penalties for defection by male and female counterparts.

One unambiguously positive result is that the literacy of at least one of the two players reduces the chances of opting out as well as the chances of defection given takeup. We found little evidence that both players being literate would improve the chances of takeup and good-equilibrium play over and above the effect of at least one being literate.

Table 6: Observed Opt Out Frequencies for Grameen Model

\begin{tabular}{l|ccc} 
& \multicolumn{3}{|c}{ Penalty } \\
& low & medium & high \\
\hline Beheira & $5 / 11$ & $4 / 10$ & $2 / 6$ \\
Fayoum & $3 / 14$ & $1 / 7$ & $0 / 7$ \\
\hline
\end{tabular}

Table 7: Observed Opt Out Frequencies for RoSCA Model

\begin{tabular}{l|ccc} 
& \multicolumn{3}{|c}{ Penalty } \\
& low & medium & high \\
\hline Beheira & $3 / 14$ & $1 / 15$ & $1 / 12$ \\
Fayoum & $3 / 14$ & $1 / 21$ & $0 / 21$ \\
\hline
\end{tabular}

Finally, there is a significant governorate effect, with more opting out and defaults conditional on takeup in the governorate of Beheira compared to Fayoum. Our data suggest that values of $q$ for pairs in Beheira may have been lower than values of $q$ for pairs in Fayoum. ${ }^{18}$ Using only the opt-out frequencies, shown in Tables 6 and 7, we can construct likelihood functions for $q$ using the relationships $q<(1+i)$ under Grameen and $q<1-p$ under RoSCA. This analysis is shown in Appendix 2. It confirms that we detect both a model and a governorate effect in the distribution of $q$, but also confirms that for each model (Grameen and RoSCA), the estimated distribution of $q$ in Fayoum first-order stochastically dominates the estimated distribution of $q$ in Beheira.

Differences in $q$ distributions, as well as the design concentrations in each governorate, thus account, at least partially, for the significant governorate effect in our statistical analysis. Pursuing this analysis of $q$ distribution at higher degrees of granularity would tax our sample sizes and is unlikely to yield useful insights. Modeling social capital with a single parameter $q$ is admittedly an oversimplification. However, this simple model has produced clean theoretical results that were supported by our experiments in the field.

\footnotetext{
${ }^{18}$ We are grateful to Chinhui Juhn for the suggestion that our governorate effect may be simply due to different $q$ values for the two governorates. We are also grateful to participants at the ESA Conference in Chicago, 2011, for suggesting that $q$ may also vary with design and payoffs, including $p$.
} 


\section{Conclusions}

The long-term goal of this research program is to investigate the viability and desirability of village-level credit unions to bridge the gap between the poor and the mainstream financial sector in majority Muslim countries. For-profit microfinance institutions and non-profit NGOs have been actively pursuing different models to bridge this gap over the past few decades. Some degree of borrower ownership and democratic governance - mainstays of contemporary credit unions - have been implemented in Grameen and other renowned models of microfinance. However, full fledged credit unions as microfinance institutions have not, to our knowledge, been advocated widely in this part of the world.

Our intuition suggested that credit unions might be more successful conduits of microfinance in societies with social and religious stigma against interest-based borrowing (in a nonprofit credit union, "interest" income would be acceptable religiously to cover costs

- indeed, microlenders in Egypt often label interest as "cost of loan," however, we have not tested this design in the current paper). Not for profit credit unions are also more likely than their for-profit MFI counterparts to avoid the urge to lend the poor more than they can afford to borrow. It is encouraging that this first experimental study has produced higher take-up and repayment rates under the guaranteed-RoSCA model (a prototype credit union) relative to a prototype Grameen model.

Our objective in this paper was not to mimic exactly the institutional structures observed in the field. For instance, both Grameen and guaranteed-RoSCA models were presented in this paper in sequential forms, which was the norm in the early years of Grameen Bank, but simultaneous loans have become the norm more recently. This paper was focused on investigating the takeup rates and default rates under the two models credit infusion from the bank on the one hand and leveraging the community's savings to finance investment or consumption smoothing on the other. Our pilot experiments suggested that the sequential structure was much easier for the subjects to understand, and therefore we used it in this study. In this regard, we were willing to sacrifice similarity to field operations in order to ensure that subjects understand the game structure fully.

Another simplification in our design is abstraction from the randomness of returns on investment - which could even be negative in the field. Of course, in any further field experiments of Grameen-style vs. guaranteed-RoSCA-style financing, we will have to account for the possibility of defaults triggered by bad realizations of random returns, whereas our experimental analysis in this paper limits defaults to moral hazard. This additional complexity of the game in the field experiment should be less troublesome because in a field experiment there will be no need to explain every branch of the extensive form to participants. 


\section{References}

Abdul Rahman, Abdul Rahim, "Islamic Microfinance: A Missing Component in Islamic Banking," Kyoto Bulletin of Islamic Area StudiesArea, 2007, pp. 38-53.

Ahmed, Habib, "Financing Microenterprises: An Analytical Study of Islamic Microfinance Institutions," Islamic Economic Studies, 2002, g (2).

Ambec, Stefan and Nicolas Treich, "Roscas as financial agreements to cope with selfcontrol problems," Journal of Development Economics, January 2007, 82 (1), 120-137.

Ashraf, Nava, Dean Karlan, and Wesley Yin, “Tying Odysseus to the Mast: Evidence from a Commitment Savings Product in the Philippines," Quarterly Journal of Economics, 2006, I 2 I (2), 635-72.

Banerjee, Abhijit V and Esther Duflo, "Do Firms Want to Borrow More ? Testing Credit Constraints Using a Directed Lending Program," Center for Economic Policy Research Working Paper, 2004, (August).

_ and _, Poor Economics: A Radical Rethinking of the Way to Fight Global Poverty, Public Affairs, 2011.

_, _, Rachel Glennerster, and Cynthia Kinnan, "The Miracle of Microfinance? Evidence from a Randomized Evaluation," JPAL Wokring Paper, 2009.

Besley, Timothy, Stephen Coate, and Glenn Loury, "On the Allocative Performance of Rotating Savings and Credit Associations," Working Papers, Princeton, Woodrow Wilson School - Development Studies 1992.

_, , , and _ , "The economics of rotating savings and credit associations," American Economic Review, October 1993, 83 (4), 792-810.

_, _, and _, "Rotating Savings and Credit Associations, CreditMarkets and Efficiency," Review Literature And Arts Of The Americas, 1994, 6I (4), 701-719.

CGAP, “Islamic Microfinance: An Emerging Market Niche,” World Bank, 2008.

_ , "Measuring Access to Financial Services Around the World," World Bank, 2009.

de Aghion, Beatriz Armendáriz and Jonathan Morduch, The Economics of Microfinance, MIT Press, 2005.

Dhumale, Rahul and Amela Sapcanin, "An Application of Islamic Banking Principles to Microfinance," UN Development Programme Techinical Note, 1998. 
Dowla, Asif and Dipal Barua, The Poor Always Pay Back: The Grameen II Story, 1 ed., Kumarian Press, Inc, 2006.

El-Gamal, Mahmoud, "Interest' and the Paradox of Contemporary Islamic Law and Finance," Fordham International Law Journal, 2003, 27 (1), 108-149.

_ , Islamic Finance: Law, Economics, and Practice, Cambridge University Press, 2006.

_ , "A Simple Fiqh-and-Economics Rationale for Mutualization in Islamic Financial Intermediation," in Nazim Ali, ed., Integrating Islamic Finance into the Mainstream: Regulation, Standardization, and Transparency, Cambridge: Islamic Finance Project, Islamic Legal Studies Program, Harvard University, 2007.

Karlan, Dean, “Social connections and group banking," Economic Journal, 2007.

— and Jonathan Zinman, "Expanding Credit Access: Using Randomized Supply Decisions to Estimate the Impacts," Review of Financial Studies, 2009.

_ and _ , "Expanding Microenterprise Credit Access : Using Randomized Supply Decisions to Estimate the Impacts in Manila ,"Working Paper, 2010, pp. 1-36.

Matin, Imran, "Repayment Performance of Grameen Bank Borrowers: The 'Unzipped' State," Savings and Development, 1997, 2 I (4), 451-473.

Obaidullah, Mohammed and Tariqullah Khan, "Islamic Microfinance Development: Challenges and Initiatives," Islamic Research \& Training Institute, 2008.

Pitt, Mark and Shahidur Khandker, "The impact of Group-Based Credit Programs on Poor Households in Bangladesh: Does the Gender of Participants Matter," Journal of Political Economy, 1998, p. 106.

Roodman, David and Jonathan Morduch, "The Impact of Microcredit on the Poor in Bangladesh : Revisiting the Evidence," Center for Global Development Working Paper, 2009.

UNDP, “UNDP Egypt Human Development Report 2008,” 2008. 


\section{Appendix I \\ Sample and Experiment Checks}

MANOVA tests failed to reject the null hypothesis of no experimenter effect, and rejected the null hypothesis of no effect of the penalty size $p$.

Table 8: Manova Tests

\begin{tabular}{l|cc} 
Experimenter & & \\
\hline Opt Out & $\mathrm{F}=0.71$ & $\mathrm{p}=.746$ \\
Equilibrium & $\mathrm{F}=0.52$ & $\mathrm{p}=.789$ \\
Defect & $\mathrm{F}=0.69$ & $\mathrm{p}=.655$ \\
& & \\
Penalty & & \\
\hline Opt Out & $\mathrm{F}=2.90$ & $\mathrm{p}=.036$ \\
Equilibrium & $\mathrm{F}=9.15$ & $\mathrm{p}=.000$ \\
Defect & $\mathrm{F}=10.77$ & $\mathrm{p}=.000$
\end{tabular}

We could not conduct a test of significance between the two neighboring villages in Beheira because we only ran experiments with Grameen in one and with RoSCA in the other, confounding village-specific and design effects. However Table 9 shows the resemblance of the main socio-demographic variables between our samples from the two Beheira villages, as well as differences from those in Fayoum. We cannot reject the hypothesis that the demographics of Feesha and Aryamon are statistically equal as expected given the proximity and similarities of the two villages. 
Table 9: Comparison of Village Demographics

\begin{tabular}{|c|c|c|c|}
\hline \multirow{2}{*}{$\begin{array}{l}\text { Governorate } \\
\text { Village }\end{array}$} & \multirow{2}{*}{$\begin{array}{c}\text { Fayoum } \\
\text { Disya }\end{array}$} & \multicolumn{2}{|c|}{ Beheira } \\
\hline & & Feesha & Aryamon \\
\hline Mean Age & 39 & 37 & 38 \\
\hline$\%$ Female & 88 & 34 & 51 \\
\hline$\%$ Literate & 27 & 70 & 64 \\
\hline \% Employed & 32 & 62 & 45 \\
\hline$\%$ Married & 76 & 78 & 63 \\
\hline$\%$ Head of $\mathrm{HH}$ & 59 & 65 & 60 \\
\hline Mean HH Income & 283 & 347 & 330 \\
\hline$\%$ Have Savings & 7 & 22 & 28 \\
\hline$\%$ Own TV & 69 & 83 & 88 \\
\hline \% Satellite Dish & 30 & 49 & 56 \\
\hline$\%$ Own Cell Phone & 27 & 53 & 43 \\
\hline Villages Equal? & & p-Value & .0752 \\
\hline Governates Equal? & & p-Value & .0000 \\
\hline
\end{tabular}




\section{Appendix 2}

\section{Construction of the Likelihood Function to Estimate Distributions of $q$}

Assuming that pairs in Fayoum draw values of $q$ i.i.d. from the distribution $\chi_{n_{F}}^{2}$, and that each pair in Beheira draw values i.i.d. from $\chi_{n_{B}}^{2}$, we can easily construct likelihood functions for the two samples as functions of the (degrees of freedom) parameters $n_{F}$ and $n_{B}$, as well as the error rates $\epsilon_{F}$ and $\epsilon_{B}$ and the counts in Tables 6 and 7.

Under our model, we should observe an opt out in the Grameen design, assuming no errors, if and only if $q<(1+i)=$ EGP 12 . Under the RoSCA design, again assuming no errors, we should observe opting out only if $q+p<1=$ EGP 10. Excluding the zero-penalty rounds, for the low penalty design ( $p=$ EGP 6 ), we should observe opting out only if $q<$ EGP 4, and for our medium and high penalty designs ( $p=$ EGP 11, 13, respectively), we should never observe opting out. To the extent that we did observe a few opts out for medium and high values of $p$, we need to allow for erroneous opts out. We will allow for such errors by assuming that every pair have a fixed probability $\epsilon$ of opting out when they shouldn't or continuing when they should opt out.

We have assumed that every pair in governorate $G, G \in\{B, F\}$, draws $q \stackrel{i . i . d .}{\sim} \chi_{n_{G}}^{2}$. Based on our model in Section 2, the decision whether to opt out or continue should depend on whether $q$ is below or above some threshold, respectively. In addition, we are allowing for a trembling-hand probability $\epsilon_{G}$ that would result in the pair choosing opt out when they should continue or vice versa. The log likelihood function for governorate $G$ (as a function of $\left.\left(n_{G}, \epsilon_{G}\right)\right)$ can be decomposed into four terms based on counts of opts out and takeups:

- For the Grameen model, for all values of $p$, if we observe \#k opts out and \#t takeups, the contribution to the log likelihood function is:

$$
\begin{aligned}
& \# k\left[\log (\overbrace{\left(1-\epsilon_{G}\right) F_{\chi_{n_{G}}^{2}}(12)}^{\text {no error, } q<12}+\overbrace{\epsilon_{G}\left(1-F_{\chi_{n_{G}}^{2}}(12)\right)}^{\text {error, } q \geq 12})\right]+ \\
& \# t\left[\log (\underbrace{\left(1-\epsilon_{G}\right)\left(1-F_{\chi_{n_{G}}^{2}}(12)\right)}_{\text {no error, } q \geq 12}+\underbrace{\epsilon_{G} F_{\chi_{n_{G}}^{2}}(12)}_{\text {error, } q<12})\right]
\end{aligned}
$$

- For the RoSCA model, for each governorate $G$, for penalty level $p=6$, if we observe $\# k$ and $\# t$ takeups, the contribution to the $\log$ likelihood function is

$$
\begin{aligned}
& \# k\left[\log \left(\left(1-\epsilon_{G}\right) F_{\chi_{n_{G}}^{2}}(4)+\epsilon_{G}\left(1-F_{\chi_{n_{G}}^{2}}(4)\right)\right)\right]+ \\
& \# t\left[\log \left(\left(1-\epsilon_{G}\right)\left(1-F_{\chi_{n_{G}}^{2}}(4)\right)+\epsilon_{G} F_{\chi_{n_{G}}^{2}}(4)\right)\right]
\end{aligned}
$$


- Finally, for the RoSCA model, for each governorate $G$, for penalty levels $p=11$ and $p=13$, if we observe \#k and \#t takeups, the contribution to the $\log$ likelihood function is simply:

$$
\# k \underbrace{\log \left(\epsilon_{G}\right)}_{\text {all errors }}+\# t \underbrace{\log \left(1-\epsilon_{G}\right)}_{\text {all no errors }}
$$

Summing up all these terms, we obtain the log likelihood function for each governorate.

Figure 5 shows the contours of the loglikelihood function, broken down by governorate and design. Our regression analysis result is reproduced in the top two figures in this panel, wherein we can see that the distribution of $q$ in Beheira puts more mass on lower values relative to Fayoum; i.e. the population in Fayoum appears to have higher social capital than the population in Beheira. The estimated densities of $q$ are $\chi_{20}^{2}$ for Fayoum and $\chi_{15}^{2}$ for Beheira, and the error rates are $7.5 \%$ for Fayoum and $15 \%$ for Beheira. The estimated densities of $q$ for the two governorates are shown in Figure 5.

However, this does not tell the entire story. The four lower plots in Figure 4, show that the distribution of $q$ is generally similar for the RoSCA design across governorates. Also, the estimated distributions of $q$ suggest higher levels of estimated social punishment under the Grameen model. This result is shown in Figure 6 for aggregated data under each model. The corresponding estimated densities of $q$ for the two models are shown in Figure 7. Therefore, as we tried to investigate differences in densities of $q$ - our parameter that measures the importance of social punishment - across governorates, our results have strongly suggested that this difference between governorates is manifest only under the Grameen design (with hindsight, this is clear in Tables $6 \& 7$ ). In other words, even if $q$ is model dependent, our results suggest that the RoSCA design should perform equally well in villages with low or high $q$ draws, as predicted by our model for reasonable values of $p$.

To check the estimation results for distributions of $q$, we also estimated the parameters of lognormal distributions, which are more difficult to portray graphically because we have three parameters - $(\mu, \sigma)$ for the lognormal and $\epsilon$ for the errors - and the results were qualitatively identical, as shown in Table 10 (where "max" means that the parameter estimates for the subsample always were at the upper boundary of allowed parameter values in fmincon, the optimization routine used in matlab to minimize the negative of log likelihood, and fminunc produced unrealistically high estimates, suggesting that the graphical approach to estimation with a single-parameter family shown in Figures 4 and 6 is more fruitful, especially given the flatness of the log likelihood functions as shown in the contour graphs). Qualitatively, the results still show higher levels of social capital in Fayoum and higher levels under the Grameen design. 

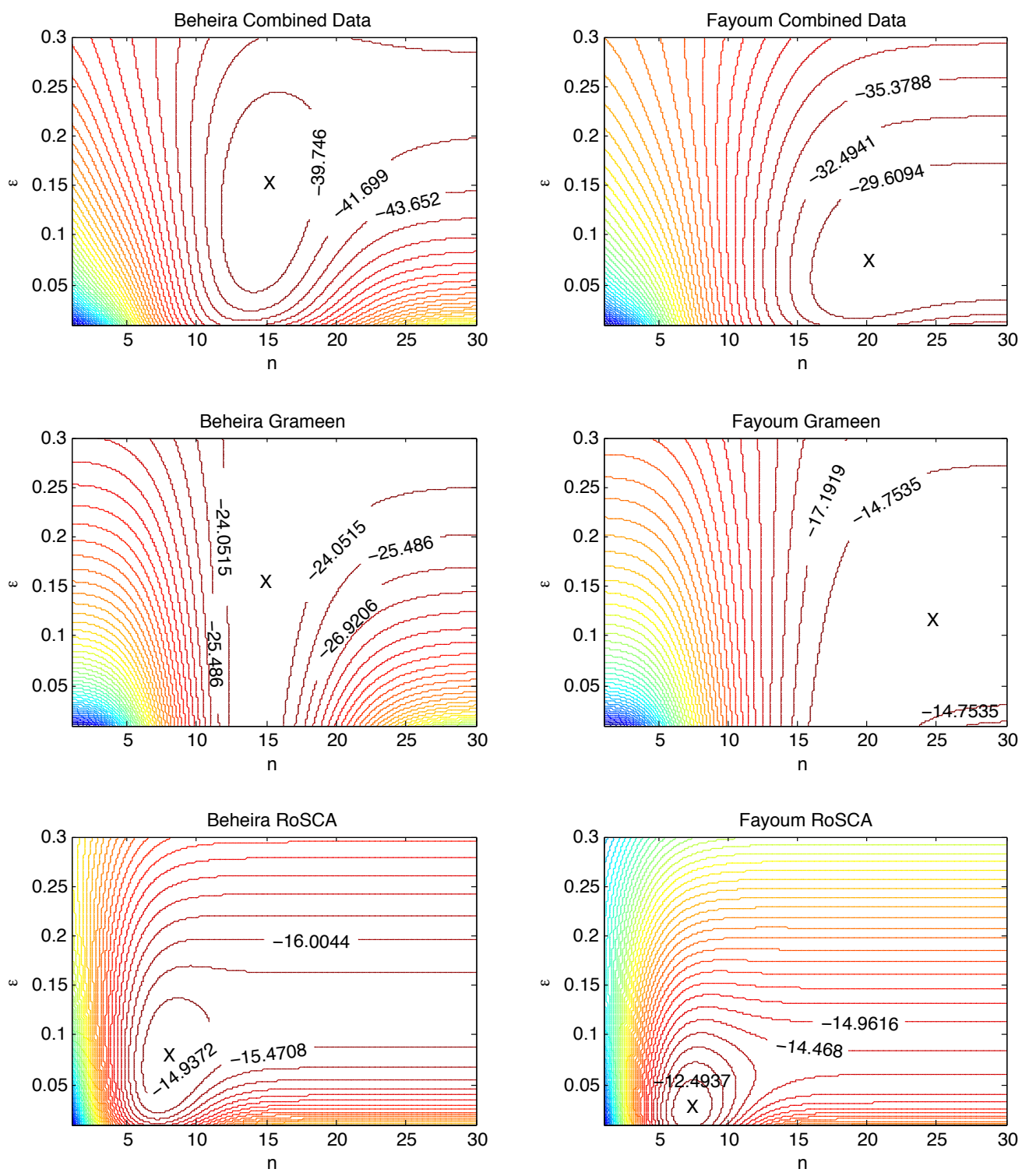

Figure 4: Log likelihood Contours for Various Subsamples 


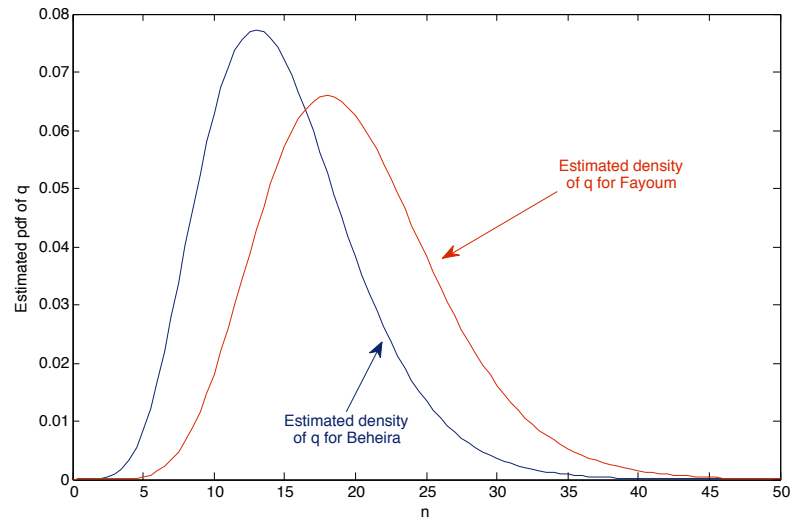

Figure 5: Estimated Densities of $q$ for Beheira and Fayoum
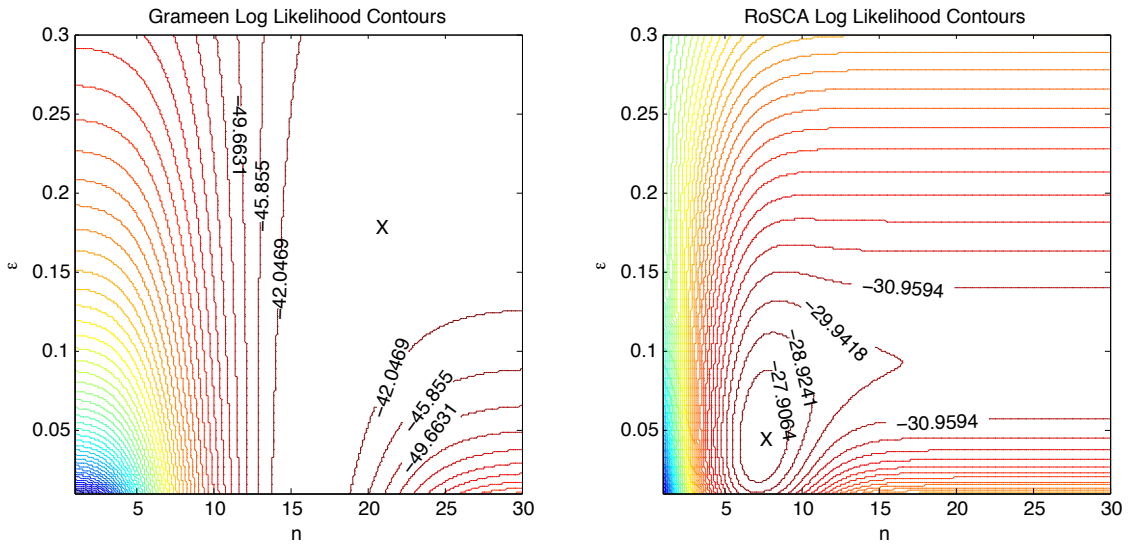

Figure 6: Log-likelihood Contours for All Data under Grameen and RoSCA Designs 


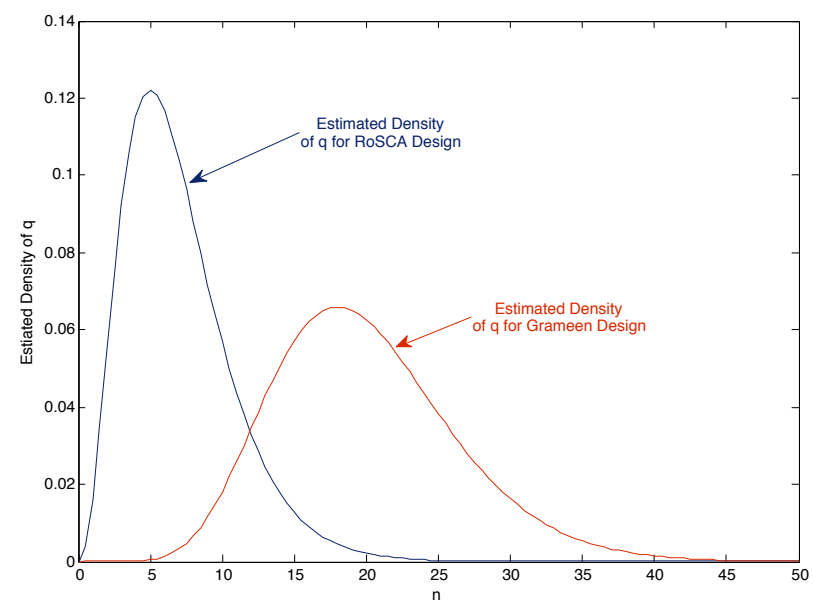

Figure 7: Estimated Densities of $q$ under Grameen and RoSCA Designs

Table 10: Maximum Likelihood Estimates (std errors in parentheses)

\begin{tabular}{l|ccc} 
Sample & $\hat{\mu}$ & $\hat{\sigma}^{2}$ & $\hat{\epsilon}$ \\
\hline Beheira (all) & 3.1088 & 1.7653 & 0.0741 \\
& $(3.0441)$ & $(6.5483)$ & $(0.4261)$ \\
\hline Beheira (Grameen) & 5.8842 & 4.2846 & 0.2945 \\
& $(3.0581)$ & $(4.4275)$ & $(0.2766)$ \\
\hline Beheira (RoSCA) & 5.6384 & 4.3578 & 0.0741 \\
& $(14.040)$ & $(5.2544)$ & $(0.1649)$ \\
\hline \hline Fayoum (all) & $\max$ & $\max$ & 0.0238 \\
& & & $(0.0257)$ \\
\hline Fayoum (Grameen) & 6.8286 & 2.1233 & 0.1014 \\
& $(25.443)$ & $(14.993)$ & $(0.1881)$ \\
\hline Fayoum (RoSCA) & 5.3387 & 4.6962 & 0.0238 \\
& $(253.30)$ & $(297.64)$ & $(0.2472)$ \\
\hline \hline Grameen (all) & 6.5515 & 3.0650 & 0.1934 \\
& $(2.9433)$ & $(2.1329)$ & $(0.0919)$ \\
\hline RoSCA (all) & 4.4077 & 0.1561 & $\max$ \\
& $\max$ & $\max$ & \\
\hline
\end{tabular}




\section{Appendix 3 \\ Translated Experimental Protocol \& Instructions}

At the beginning of each session, subjects sat in a large hall, listened to the instructions below and watched an example game being demonstrated, and then questions were answered in public. They were neither shown the extensive form diagrams above nor handed a copy of these instructions.

\section{Game Instructions-Grameen Style}

Introductory Instructions:

1. Explain the concept: "Everyone will get the same amount of starting capital. There will be an investment opportunity available, but it will cost more than the amount of capital each participant is initially given. You will have the opportunity to invest by borrowing with interest from the bank. Your partner will have the same opportunity if the original loan is repaid. In the case of non-payment of any of the loans, the bank will fine both parties. To avoid a fine, anyone can pay the other's debt to the Bank"

2. Explain the details of the game to the participants using paper money. (See Below)

3. Answer questions from participants during the commentary.

4. Inform the participants that they can inquire about any of the details of the experiment at any time.

5. Inform that the participants that they can communicate and exchange views during the experiment.

6. Inform the participants that their role will be selected (first or second mover ) by drawing lots (flipping a coin).

7. Ask a participant if they would like to choose Heads or Tails.

8. Tell the participants which order they will proceed in and give them their initial endowment (14 pounds)

9. Start the experiment following the steps outlined below.

Experiment Instructions: (The following is the high punishment case.)

1. Each participant gets to 14 pounds. (Give each participant 14 EGP)

2. Inform the participants as follows: The Bank's investment opportunity requires 20 pounds with a guaranteed return of 4 pounds. The Bank will receive interest payments of 2 pounds on any loan of 10 pounds. 
3. Begin the game: Ask participants: Do you want to get a loan from the Bank for 10 pounds to repay later, with interest, 12 pounds? (In case of refusal to take a loan, end the experiment. Otherwise continue to No. 4)

4. Ask the first participant: You've received the loan and invested, and now you've got 28 pounds. Do you want to repay the loan or not? (If they do not pay to No. 6, if they paid continue to No. 5)

5. Declare the following: The participant paid the first loan and now has 16 pounds. (Go to No. 8)

6. Declare the following: the first participant did not pay. Ask the second participant: Do you want to pay the debt of the participant (12 pounds)? You will then be owed this amount by the first participant? Or you can be subjected to the Bank's punishment (X pounds) on each of you? (If second doesn't pay for first, go to 12, otherwise continue to No. 7)

7. Declare the following: the second participant repaid the bank on behalf of the first participant and currently has 2 pounds. Ask the first participant: Will you repay your debt to the second participant? (12 pounds) (If the first participant does not pay his debt to the second participant end the experiment otherwise continue to No. 8)

8. Ask the second participant: Do you want to get a loan from the Bank for 10 pounds to repay later, with interest, a total of 12 pounds? (If no- End Game, otherwise continue to No. 9)

9. Inform the second participant: You've gotten a loan and invested it, and now you've got 28 pounds. Do you want to repay the loan (12 pounds)? (If he pays back End Game, if he doesn't pay continue to No. 10)

10. Declare the following: the second person does not pay. Ask the first participant: Do you want to pay the debt of the second participant (12 pounds) or would you instead take the bank's fine (X pounds) on each of you? (If the first participant doesn't pay for the second, go to 13. Otherwise continue to No. 11)

11. Declare the following: the first participant paid for the second participant and each of you have 16 pounds. (End Game)

12. Declare the following: the first participant's loan has not been paid. There is a punishment (X pounds) on each of you. The first participant has 15 pounds and the second has 1 pound. (End Game)

13. Declared the following: the second participant's loan was not paid. There is a punishment (X pounds) on each of you. The first participant has 3 pounds and the second had 15 pounds. (End Game) 


\section{Game Instructions- RoSCA Style}

Introductory Instructions:

1. Explain the concept: "Everyone will get the same amount of capital. There is an investment opportunity available, but it will cost more than the amount of capital each participant currently has. You will have the opportunity to establish RoSCAs which can enable both of you to invest. The Bank will insure these RoSCAs. For example, if your partner refuses to repay the Rosca, you will be reimbursed by the Bank in the form of a loan to the defaulter. If the loan is not subsequently repaid the Bank will levy a fine on both parties. If you agree to join in the Rosca you will need to pay the Bank a small fee."

2. Explain the details of the game to the participants using paper money. (See Below)

3. Answer questions from participants during the commentary.

4. Inform the participants that they can inquire about any of the details of the experiment at any time.

5. Inform also that the participants can communicate and exchange views during the experiment.

6. Inform the participants that their role will be selected (first or second mover) by drawing lots.

7. Ask a participant if they would like to choose Heads or Tails.

8. Tell the participants which order they will proceed in and give them their initial endowment (14 pounds)

9. Start the experiment following the steps outlined below.

Experiment Instructions:

1. Each participant gets to 14 pounds. (Give each participant 14 EGP)

2. Inform the participants as follows: The Bank's investment opportunity requires 20 pounds with a guaranteed return of 4 pounds. The Bank fee for guaranteeing the Rosca is 1 pound from each participant. In case of non-payment of the Rosca the defaulting party becomes indebted to the Bank in the amount of 12 pounds.

3. Begin the game:Ask participants: Would you like to partake in Bank Guaranteed Rosca's? The first mover will be able to invest and after repayment the second mover will also have the opportunity to invest. (In case of refusal, end the experiment. Otherwise continue to No. 4) 
4. Ask the first participant: You've received the Rosca Payment and invested, and now you've got 27 pounds. Do you want to repay the Rosca? (If they do not pay to No. 6 , if they paid continue to No. 5)

5. Declare the following: The participant repaid the Rosca and now has 17 pounds. (Go to No. 8)

6. Declare the following: the first participant did not repay the Rosca. The Bank steps in and pays the second participant. The first participant is now indebted to the bank for the sum of 12 pounds. (Go to No. 7)

7. Ask the first participant: Will you repay the bank the money owed? (12 pounds) (If no go to No. 13, otherwise go to No. 8)

8. Declare; The first participant has 17 pounds and the second has 13. Ask the first participant: Do you want to fulfill your promise and continue the second round of the Rosca by loaning 10 pounds to your partner? (If no- End Game, otherwise continue to No. 9)

9. Inform the second participant: You've gotten a Rosca Payment and invested it, and now you've got 27 pounds. Do you want to repay the Rosca (10 pounds)? (If he pays back move to No. 10, if he doesn't pay continue to No. 11)

10. Declare the following: the second person now has 17 pounds. (End Game)

11. Declare the following: the second person does not pay. The bank steps in and pays on their behalf. The second player is now indebted to the bank for the sum of 12 pounds. (Continue to No. 12)

12. Ask the second participant: Will you repay your debt (12 pounds) to the Bank or not? (If the participant does not pay his debt to bank the second, go to No. 14 and only ended the test)

13. Declare the following: the first participant did not pay his debt to the Bank, The bank penalizes (X pounds) each of you. The first participant now has 14 pounds and the second has a zero pounds. (End Game)

14. Declare the following: the second person did not pay his debt to the Bank. The bank penalizes (X pounds) each of you. The first participant now has 4 pounds and the second has 14 pounds. (End Game) 